\title{
CRÍTICA DE LEVINAS À ESTRUTURA DA SUBJETIVIDADE KANTIANA
}

\author{
Evaldo Antônio Kuiava*
}

SINTESE - Conforme Lévinas, a filosofia crítica kantiana ainda é insuficiente para estabelecer uma autêntica relação com outrem, à altura do humano. Isso ocorre apesar de Kant determinar os limites, o alcance e o valor da razão, concluindo pela redução do campo do conhecimento racional aos objetos de experiência possivel, o que significou a negação da possibilidade de cognoscibilidade dos objetos da metafísica e da religiāo. Tal insuficiência consiste essencialmente na concepção da subjetividade como atividade espontânea. Nesse sentido, Lévinas propõe uma destituição do eu autônomo do seu poder de legislar os princípios que regem a lei moral. Ele substitui o principio da autonomia pelo princípio da heteronomia, propondo que a heteronomia é a condição de possibilidade para chegar à autonomia.

PALAVRAS-CHAVE - Transcendental. Subjetividade. Lévinas. Kant. Alteridade. Ética.
ABSTRACT - According to Lévinas, Kant's critical philosophy is still insufficient to establish an authentic relationship with the other, insofar as humanness is concerned. This occurs despite Kant's efforts to determine the limits, the scope and the value of reason, resulting in the reduction of the field of rational knowledge to the objects of possible experience, thereby denying the possibility of rational knowledge of metaphysical and religious objects. Such an insufficiency essentially consists in the conception of subjectivity as a spontaneous activity. In this sense, Lévinas proposes a destitution of the autonomous self from his legislative power to rule the principles of the moral law, and replaces the autonomous principle by the heteronomous one, so as to propose that heteronomy is a condition of possibility in order to reach autonomy.

KEY WORDS - Transcendental Subjectivity. Lévinas. Kant. Otherness. Ethics.

A tarefa da filosofia kantiana consiste em explicitar os fundamentos do conhecimento e da ação moral. A capacidade de objetivação e de universalização do conhecimento teórico, bem como a determinação do princípio de validação das normas do agir humano, encontram-se na própria estrutura da subjetividade do eu. Em seus escritos críticos, Kant expõe a estrutura e a trajetória da subjetividade em três níveis: a consciência empírica; a posição do sujeito transcendental ou a consciência em geral, equivalente ao eu penso, e a dimensão do sujeito inteligível, numênico. ${ }^{1} \mathrm{Na}$ primeira acepção situa-se o sujeito da sensibilidade, o eu psicológi-

* Professor do Departamento de Filosofia da Universidade de Caxias do Sul (UCS). Doutorando em Filosofia na Pontifícia Universidade Católica do Rio Grande do Sul (PUCRS).

1 Cf. CIFUENTES, A. Llano. Fenómeno y trascendencia en Kant. Pamplona: Universidad de Navarra, 1993. p. 306-307.

\begin{tabular}{|l|l|l|l|l|l|}
\hline VERITAS & Porto Alegre & v. 44 & n. 2 & Junho 1999 & p. $297-310$ \\
\hline
\end{tabular}


co, objeto do sentido interno, o qual recebe passivamente as afecções externas, e as conforma espaço-temporalmente. No segundo significado, o sujeito transcendental é o fundamento e a condição subjetiva do conhecimento intelectual. Ele é a base de toda objetivação teórica possivel e, enquanto inteligivel, encontra-se fora do entrelaçamento dos fenômenos. Seụs objetos ${ }^{2}$ não são dados na experiência, isto é, a sua capacidade objetivante não está mais limitada aos dados empíricos, e se estende às coisas em si, outrora inacessiveis.

$\mathrm{O}$ eu, enquanto empírico, psicológico, faz parte da natureza, ${ }^{3}$ mas devido ao seu caráter trascendental é racional, finito e, por ser inteligivel, é membro do reino dos fins, ${ }^{4}$ necessitando de leis a priori para determinar o seu conhecimento e a sua conduta moral. Com esta modalidade apriorística ele impõe a sua legislação, ${ }^{5}$ quer à natureza, quer à̀s próprias ações. ${ }^{6} \mathrm{O}$ processo acontece na medida em que a sensibilidade recebe passivamente as sensações, o entendimento organiza e sintetiza os dados recebidos e ordenados no tempo e no espaço e a razăo realiza a síntese das categorias que são unificadas pela consciência do eu transcendental. Devido a sua autonomia lógica em relação aos fenômenos, o eu transcendental, enquanto autoconsciência, é legislador da natureza. ${ }^{7}$ É transcendental a subjetividade dos princípios que regem o conhecimento. São as condições șubjetivas que fazem possivel a verdade científica dos fenômenos e a verdade universal da lei moral. Isto é, existem leis a priori da natureza que derivam da unidade da consciência, e leis a priori da razão que podem provir da perspectiva da liberdade. No primeiro caso são acerca do verdadeiro e do falso, desempenham seu papel na descrição, na predição e na expliçação da realidade. No segundo caso, sã̉o leis práticas que dizem respeito à ação.

Os aspectos da subjetividade estão sempre correlatos à liberdade do sujeito. Embora, na dimensão empírica, praticamente não exista a liberdade, senão um mero arbítrio instintivo, na esfera transcendental, o eu é ativo, espontâneo, capaz de constituir o conhecimento dos fenộmenos. Tratar da liberdade propriamente

2 Entende-se por objeto não apenas aquilo que é dado sensivelmente, mas também o conhecido por determinação conceitual ou mediante juízos. Kant além de atribuir um uso restrito a este termo, a saber, o objeto empírico, a coisa natural, considera também um significado mais amplo. Neste caso, trata-se do objeto da razão prática, o qual é resultado de uma ação livre. Para um estudo mais detalhado consultar (B 671 s) e (A 101s). Para as obras de Kant serão usadas as seguintes siglas: A Crítica da razão prática; B - Crítica da razão pura; BA - Fundamentação da Metafísica dos costumes, Prol - Prolegômenos a toda Metafisica futura.

3 O termo natureza, em sentido lato, significa a realidade determinada por leis gerais, e designa simplesmente uma constituição formal: a regularidade, a ordenação segụndo leiş gerais (Prol § 14, nota 68). Para uma exemplificação mais ampla ver na Crítica da Razão Pura (B 446, em nota).

4 Por reino dos fins Kant entende a ligação sistemática, por leis comuns, de vários seres dotados de razão. Kant também se refere ao reino da natureza sob o ponto de vista teleológico, mas estritamente, a noção de reino não se aplica a toda a união, mas apenas àquela dọs seres racionais (KANT, Immanuel. Fundamentação da metafisica dos costumes. Trad. Paulo Quintela. Lisbọa: EdiÇões 70, p. 75, BA 74).

5 É o sujeito, com a sua capacidade intelectual, quem prescreve as leis à natureza e não a natureza que impōe as leis ao entendimento humano. A ordem das coisas é formada pela atividade intelectual; ou seja, as relaçōes, as conexões, a ordem dos dados șensíveis são estabelecidos pelo sujeito pensante.

6 Cf. LACROIX, Jean. Kant e o kantismo. Porto-Portugal: Rés, s.d., p. 98-99.

7 "O entendimento não extrai as suas leis (a prion) da natureza, mas prescreve-as" (Prol. § 36 ). 
dita somente é possivel a partir da dimensão inteligível - numênica - do sujeito. ${ }^{8}$ A espontaneidade do entendimento é uma certa forma analógica da liberdade. Todavia esta espontaneidade faz referência somente à forma dos objetos e do seu conhecimento, enquanto que a matéria tem que ser dada. $\mathrm{Na}$ eventualidade da liberdade prática, ela será o único fundamento dos seus próprios objetos, isto é, a liberdade supõe uma absoluta autonomia do eu com respeito aos fenômenos da natureza sobre os quais pode operar ativamente e, no que tange à moralidade, é capaz de, sem interferência externa, determinar a lei moral como um "fato da razão"9 pura prática.

O essencial é que a busca da objetividade na ciência, assim como a universalidade da lei moral em Kant, se fundamentam em um recurso à subjetividade. ${ }^{10} \mathrm{~A}$ existência dos objetos fora do eu e a fundamentação da realidade fenomênica, no âmbito teórico e, a realidade numênica, na esfera prática, dependem da atividade construtora do próprio sujeito autônomo. Nesse sentido, as respostas de Kant às suas famosas indagações, o que se pode saber, o que se deve fazer, o que cabe esperar $\mathrm{e}$, por último, o que é a homem, consideram também a alteridade? A alteridade, manifestada no "rosto" do outro homem, não trará novidades à subjetividade kantiana, mas que devido a sua estrutura monológica ela não consegue intuir? Evidentemente, não é esta a preocupação de Kant em toda a sua filosofia crítica. Entretanto, se este questionamento tem sentido, ao nível de relações intersubjetivas, a maneira kantiana de conceber a subjetividade humana terá que ser repensada.

Embora Kant não tenha tratado da questão da intersubjetividade propriamente dita, é possível extrair como conseqüência lógica a sua posição em relação a este problema. A intersubjetividade - aquilo que concerne às relações entre vários sujeitos - se constitui antes de mais nada no próprio sujeito que universaliza o conhecimento. $\mathrm{O}$ eu transcendental mantém uma esfera que não é apenas individual subjetiva, pois as suas estruturas formais a priori são universais, válidas para todos os sujeitos. Assim ele inclui todos os indivíduos, formando uma comunidade a priori universal. Desse modo, para Kant, os processos de objetivação devem ser os mesmos para todo o ser humano. A objetividade está ligada à intersubjetividade. $\mathrm{E}$ esta somente se manifesta em relação às estruturas a priori que possibilitam a objetivação, ou seja, naquilo que é comum a todos. ${ }^{11} \mathrm{~A}$ intersubjetividade ocorre não porque 0 eu mantém uma relação com outrem, mas porque todos operam do mesmo modo em relação à realidade fenomênica. Mas, esta estrutura transcendental intersubjetiva será suficiente para abarcar o problema do

8 Cf. Cifuentes, op. cit., p. 307.

9 Para Kant a Lei Moral é um dado úniço e exclusivo da razão, a qual não precisa ser justificada ou provada, Ela se impõe à consciência como um "fato da razão" (ein Faktum der Vernunf, KpV A 56).

10 Entende-se por subjetividade o conjunto das faculdades cognitivas. Já em termos mais amplos pode-se afirmar que se trata de todos os fenômenos psíquicos da consciência.

11 " $\mathrm{E}$ justamente pelo fato de esta atividade organizadora e formadora do espírito humano ser comum a todos os sujeitos, [que] Kant atribui ao homem uma subjetividade que ele chama de 'normal', e, por isso mesmo, objetiva, porque dela todos somos partícipes, e é justamente graças a esta normalidade de nossa natureza espiritual que é superado o relativismo cético de David Hume" (Galeffi, op. cit., p. 107). 
outro como absolutamente outrem? Como é possivel o conhecimento do outro, ou seja, quais são as condições que possibilitariam uma experiência do outro e que alcance significativo teria tal experiência. ${ }^{12}$

De acordo com a descrição dada, e tomando por base os pressupostos epistemológicos, pode-se sustentar a tese de que o conhecimento do outro não se reveste de nenhuma característica peculiar para Kant. A manifestação do outro não é.diferenciada da apresentação das coisas. $\mathrm{Na}$ afecção, o eu percebe o outro como a si mesmo, enquanto fenômeno, objeto de experiência. O outro torna-se para o eu um objeto configurado como sintese realizada conjuntamente pelas formas a priori da sensibilidade e pelas categorias do entendimento. ${ }^{13}$ Face ao exposto poder-se-ia dizer: nesta estrutura teórica da subjetividade transcendental não se produz o humano, o respeito pelo outro ser. Ao contrário, realiza-se somente a objetivação. No sistema teórico, o outro não se constitui como outro.

Contudo, na busca de explicitação da constituição transcendental da consciência universal, e de não aceitar nada fora da sua esfera, Kant terá realmente esquecido a alteridade? Ainda na Crítica da Razão Pura evidencia-se a possibilidade de considerar o outro para além da objetivação, momento em que para ele a realidade não se esgota no fenômeno, embora somente esse seja objeto de conhecimento. $\mathrm{O}$ autor parece apontar uma saída para a problemática da objetivação na medida em que a dimensão numênica, da qual o homem participa, não é objeto de conhecimento. Neste sentido, a alteridade, enquanto númeno, não poderá ser objetivada e escapará a toda e qualquer determinação espaço-temporal. Justiça se faça a Kant, levando em consideração a atividade cognoscitiva, pois desde a sua Primeira Crítica, o eu só poderá conhecer a aparência fenomênica do outro e não como um em si incondicionado.

Na medida em que se confere à realidade humana a metódica distinção kantiana entre fenômeno e númeno, ${ }^{14}$ e tomando por base a sua doutrina do idealismo transcendental, o ser humano, enquanto fenômeno, se encontra configurado pelas determinações da natureza e, desse modo, torna-se passível de estudo e de análise, seja através da ciência, seja por meio da especulação racional. ${ }^{15}$ Mas, enquanto númeno, foge de qualquer especificação cognitiva. $\mathrm{O}$ que está além do fenômeno é a coisa em si, o incondicionado, o numênico, o qual pode ser pensado, mas não pode ser conhecido dentro da estrutura teórica da subjetividade humana.

A relação humana, desde a perspectiva kantiana, deve seguir uma outra ordem. Esta ordem não pode ser buscada nas estruturas da consciência teórica porque seu interesse teórico deve subordinar-se ao seu interesse prático (A 215). Kant parece ser claro quando afirma que o absoluto, ou a coisa em si, não é um conteúdo válido para a intuição sensível e para o entendimento humano, mas para

12 Cf. MECA, Diego Sánchez. Martin Buber. Fundamento existencial de la intercomunication, p. 44.

13 Cf. Meca, op. cit., p. 45.

14 Embora Kant já tenha feito a distinção entre os dois mundos - o sensivel (fenomênico) e o inteligivel (numênico) - na Dissertatio de 1770, a sua afirmação de que a realidade humana participa destes dois mundos encontra-se, especificamente, na Fundamentação da Metafísica dos Costumes (BA 107-109) e no Prefácio da Crítica da razão prática (A 9-13).

Cf. Meca, op. cit., p. 45. 
uma outra ciência, não da natureza, mas a dos costumes. Embora ele não tenha elaborado uma resposta, em suas obras, à sua própria indagação "o que é o homem?", a sua filosofia volta-se para a questão do homem e para sua dignidade. Esta constatação se sustenta na medida em que para ele a pessoa humana, dotada de razão e vontade, deve ser concebida como um fim em si mesma e jamais como um meio. E, enquanto tal, a sua existência tem um valor absoluto. "Por haver-se tornado racional, a vocação moral necessariamente envolve um reconhecimento reciproco". ${ }^{16}$ A universalidade da lei somente pode ser entendida se integrar o outro no processo da determinação da moralidade. Do contrário, não haveria nenhum sentido falar sobre ações morais.

Para Kant, o princípio da autonomia da vontade, ou a capacidade de autolegislar, tem como pressuposto de que todo e qualquer agente racional possui este poder. Mas, é preciso que esta potencialidade de autodeterminação mantenha sempre presente a idéia de que o fundamento da moralidade somente pode ser atingido quando o agente considera a si e a todo o outro ser de sua espécie sempre como fim em si mesmo. Um dos méritos de Kant localiza-se na percepção de que a subjetividade humana não se reduz ao uso teórico-cognoscitivo. O ser humano é capaz de determinar os objetivos da sua ação, colocando-se como sujeito dos seus próprios fins. A segunda fórmula do imperativo categórico, qual seja, "age de tal maneira que uses a humanidade, tanto na tua pessoa como na pessoa de qualquer outro, sempre e simultaneamente como fim e nunca simplesmente como meio" (BA 66), demonstra claramente que a pessoa humana não deve ser considerada ou ser reduzida a qualquer sistema concernente a qualquer atividade humana. $\mathrm{O}$ outro não deve ser reduzido a um objeto determinado pelo eu.

No entanto, o objeto do discurso prático, a saber, a lei moral, não é resultado de uma experiência intersubjetiva, senão da própria autonomia do sujeito racional. Toda relação com a alteridade é uma consequêencia do imperativo categórico. A determinação da moralidade não é compartilhada com o outrem concreto, mas se encerra na própria subjetividade do eu. Neste contexto, qualquer relação com 0 outro não tem lugar, porque a única relação que existe é a vontade consigo mesma, na medida em que ela é determinada exclusivamente pela razão. A lei moral é uma proposição sintética a priori, e é fundada sem o recurso de qualquer elemento intersubjetivo. Ela é um dado exclusivo da razão autônoma e não necessita de nenhuma justificação de ordem interpessoal.

Sob o ponto de vista de quem formula a lei moral, a consideração de outrem não passa de uma idéia, um pressuposto da razão. Cada agente, enquanto membro da comunidade, deve legislar livremente e se submeter à própria legislação. Veja-se que, neste contexto, a alteridade apenas corrobora o fato da universalidade da lei. Como se percebe, neste esquema mental, o outro como totalmente outro desaparece, ou seja, tende a ser reduzido ao mesmo, a uma totalidade. A sua condição é de idem e não de alter. Sendo assim, a análise da estrutura da subjetividade, a partir da Crítica da Razão Pura, assim como da Crítica da Razão Prática, revela que não existe a possibilidade de uma relação intersubjetiva de modo direto, frente-a-frente, entre os agentes racionais.

16 Cf. LEBRUN, Gérard. Uma escatologia para a moral. In: KANT, Immanuel. Idéia de uma históna universal de um ponto de vista cosmopolita. Såo Paulo: Brasiliense, 1986. p. 80. 
Entretanto, na Crítica do juízo Kant admite uma relação direta entre indivíduos singulares, sem mediçã́o de conceitos. ${ }^{17}$ Para Kant a sensação (estética) dos sentidos, que por sua vez é subjetiva (privada), é comunicável aos outros independente de conceitos. ${ }^{18}$ Neste sentido, Hannah Arendt percebe, no terreno da estética kantiana, a perspectiva de uma potencial interação entre os agentes racionais, uma relação intersubjetiva, uma comunicação direta entre indivíduos singulares, frente-a-frente. ${ }^{19}$ Mas, isto só é possível a partir do pressuposto da existência de uma estrutura universal comum a todos. Assim, um juízo de gosto estético se fundamenta em um sentimento comunitário, denominado por Kant sensus communis. ${ }^{20}$

A sensação estética é comunicada aos outros sem mediaçã̃o de conceitos $a$ priori e sem interesses privados. Entretanto, ela deve ser necessariamente universal. Essa universalidade, é claro, não provém da experiência. Ela é um prossuposto, a priori, do prazer estético. Com efeito, isso não coloca todos os membros da comunidade no mesmo sistema? A possibilidade da comunicabilidade das sensações estéticas, entre o eu e os outros, está enraizada na pertença a uma estrutura, ou seja, a uma natureza comum (sensus communis). Neste contexto, a alteridade figura, novamente, como uma confirmação de uma subjetividade comum, garantindo a concordância das sensações estéticas. Como se percebe, a comunicação direta, sem mediação de conceitos da sensaçăo estética, está limitada a um pressuposto, a um sentimento comum. Isto significa que a relação intersubjetiva se fecha dentro de um horizonte em que tudo se encerra no mesmo. Ou seja, o eu e os outros possuem uma natureza comum, um sentido comunitário (sensus communis), o qual é o fundamento da comunicação do gosto estético. Disso se conclui que a manifestação das diferenças, na relação dircursiva, frente-a-frente, sem mediação, tende a ser anulada, uma vez que o prazer estético deve necessariamente ser universal. ${ }^{21}$

17 Por exemplo, quando Kant escreve que "o gosto é a faculdade de ajuizar a priori a comunicabilidade dos sentimentos que são ligados a uma representação dada (sem mediação de um conceito)" (Kant, Crítica da faculdade do juizo, § 40).

18 "O juízo estético abstrai de todos os 'interesses' do observador. Não olha o objeto como um meio para os fins do observador mas como fim em si próprio (embora não um fim moral)" (Cf. Scruton, op. cit., p. 148).

19 ARENDT, Hannah. Liçốes sobre a filosofia política de Kant. p. 90.

20 "Por sensus communis, porém, se tem que entender a idéia de um sentido comunitário (gemeinschaftlichen), isto é, de uma faculdade de ajuizamento que em sua reflexảo toma em consideração em pensamento (a prion) o modelo de representação de qualquer outro, como que para ater o seu juizo à inteira razão humana e assim escapar à ilusão que, a partir de condições privadas subjetivas - as quais facilmente poderiam ser tomadas por objetivas - teria influência prejudicial sobre o juizo" (Cf. Kant, Critica da faculdade do juizo, § 40).

21 Alain David, no seu estudo, "Le nom de la finitude. De Lévinas a Kant". (In: ROLLAND, J., recop. Les cahiers de la nuit surveillé. Emmanuel Lévinas. Paris: Verdier, 1984), procura estabelecer uma relação da noção de alteridade Levinasiana com a teoria estética de Kant. "Para David, la singularidad no se apresenta como fenómeno (analizable en términos de intuición sensible y concepto), sino como signo primario que se da libremente al otro como símbolo de la significación misma (p. 280281). Y si esta significación es, levinasianamente, moral, estamos muy próximos a la visión kantiana del (objeto bello) singular como simbolo de moralidad" (Cf. REGUERA, G. Bello. La construccion de la alteridad en Kant y Lévinas. In. MUGUERZA, Javier; ARAMAYO, R. Rodriguez, orgs. Kant después de Kant. p. 590). Na visão de Reguera, David faz uma interpretação forçada ao considerar a 
Sendo assim, no entender de Lévinas, a filosofia crítica kantiana, apesar de determinar os limites, o alcance e o valor da razão, concluindo pela redução do campo do conhecimento racional aos objetos de experiência possivel, o que significou a negação da possibilidade de conhecimento racional dos objetos da metafísica e da religião, ainda é insuficiente para estabelecer uma autêntica relação com outrem, à altura do humano. Esta insuficiência consiste essencialmente na concepção da subjetividade como uma atividade espontânea. Conseqüentemente, não percebe "[...] o brilho da exterioridade ou da transcendência no rosto de outrem". ${ }^{22}$ Ao contrário, busca a sua apropriação, reduzindo toda relação intersubjetiva a uma forma lógica e conceitual. ${ }^{23}$

O eu kantiano persiste na imanência, isto é, fechado em si mesmo, não chega ao outro, à exterioridade, mesmo porque depara-se com os seus limites na ação cognoscitiva. A preocupação de Kant não é buscar um modo de acesso ao transcendente, mas em assegurar a autonomia do sujeito. Este "giro copernicano", em que o sujeito é fundamento do conhecimento e da lei moral, precisa ser invertido, pois mesmo que o eu pratique eventuais atos de bondade, não significa que a partir da autonomia da vontade, da liberdade racional, se possa ter como o único referencial para a instauração de uma ética que satisfaça às exigências mais profundas da humanidade.

Lévinas, para superar as limitações da filosofia da consciência monológica, propõe uma transformação radical da razão prática de Kant. ${ }^{24}$ Para destituir o eu do seu poder e da sua capacidade de reduzir toda a realidade ao seu sistema, susbtitui a consciência monológica por uma consciência ética, capaz de acolher a exterioridade, o Outro. Neste sentido, faz uma reconstrução tanto da ética como da relação de alteridade. O Outro passa a ter prioridade sobre o Mesmo, isto é, sobre o Eu que se fixa na sua identidade e não reconhece nada além de si (TI XII). Este procedimento consiste em um novo "giro copernicano" e aparece como uma alternativa ao pensamento transcendental kantiano. $O$ processo acontece a partir da reconstrução da subjetividade e do sentido do humano. O ponto de partida da sua reflexão não são mais, como o foi em Kant, os juízos sintéticos a priori ou os imperativos como proposições práticas sintéticas a priori, mas a descrição da

comunicação estética como a forma verdadeira de comunicação e ao identificá-la com a relação ética de Lévinas. Arendt (op. cit., p. 90) também percebe, a partir da estética kantiana, a possibilidade de uma verdadeira relação intersubjetiva sem nenhuma mediação conceitual. Embora isto parece vir de encontro ao que Lévinas procura estabelecer para a relação intersubjetiva, a sua filosofia tem como ponto-chave a relação ética e não a estética.

22 "[...] l'éclat de l'exteriorité ou de la transcendance dans le visage d'autrui" (TI préface). Para as obras de Lévinas serão usadas as seguintes abreviaturas: AE - Autrement qu'Etre ou Au-délà de IEssence, CNI - La Conscience non-intentionnelle. In: Entre Nous; DVI - De Dieu qui Vient à IIdée, EDE - En Découvrant l'Existence avec Husserl et Hejdegger, EE - De IExistence à I Existant, EI - Éthique et Infini, EN - Entre Nous, HAH - Humanisme de l'Autre Homme, NP Noms propres, TI - Totalité et Infini,

23 Para Lévinas, "la Critique de la raison pure, motivée notamment, dans l'histoire effective de la raison, par l'échec de son usage philosophique dans les contradictions formelles auxquelles aboutit sa longue errance à la recherche de la vénté absolve au-delà du donné et débordant l'envergure de la critique de l'aperception transcendentale, n'a pas aboli comme non-sens le sens même du méta de la métaphysique" (TRI 278).

24 Cf. REGUERA, G. Bello. La construcción de la alteridad en Kant y Lévinas. In: Kant después de Kant, p. 594. 
própria constituição da subjetividade, ou seja, o modo pelo qual acontece a identificação do eu, a partir da corporeidade, da sensibilidade, da afetividade, do gozo da vida.

A busca da vida feliz no mundo do gozo, da economia, da produção teórica, são visadas pelo eu em virtude de sua própria satisfação. No entanto, esses modos, embora necessários para a sua constituição como ser único e separado, podem ser conduzidos para além das necessidades em que o gozo, a economia e o saber não são a última palavra. Nesse caso, o eu se reduziria a animal racional, faminto, egoísta e soberano em que tudo lhe seria permitido. Na busca da identificação, excluída toda exterioridade, a consciência não teria limites e problemas, ou seja, a interioridade se satisfaria no gozo, seria capaz de sacrificar os outros em favor de sua felicidade e do seu reconhecimento. Neste sentido, Lévinas perguntase: "a intencionalidade é o único modo de 'doação de sentido'? O significativo é ele sempre correlativo de uma tematização e de uma representação?"25 A intencionalidade, em que o pensamento permanecesse adequação ao objeto, define a consciência em seu nível fundamental?

O que impede a totalização, sem qualquer possibilidade de integrar a relação do Mesmo com o Outro num todo, é uma "situação anunciada por Descartes, na qual o eu penso mantém com o Infinito, que ele não pode de modo algum conter e do qual está separado, uma relação chamada Idéia do Infinito". ${ }^{26}$ É a partir do Infinito que se percebe o modo pelo qual a consciência monológica, fonte de todo o sentido, é destituída do seu poder de autonomia.

A idéia do infinito não permite que o Eu e o Outro possam ser reduzidos à mesma totalidade conceitual, a qual poderia englobá-los. Não importa que essa totalidade conceitual proceda do eu, do outro ou de um terceiro. A diferença, isto é, a separação entre o Mesmo e o Outro é de fato irredutível, uma distância infinita que nenhuma definição ou categorização gnoseológica consegue desfazer. É como o númeno, na filosofia kantiana. No entanto, tal idéia incomensurável não significa simplesmente que o eu seja incapaz de compreender ou apreender conceitualmente o outro, mas que o outro não se deixa integrar no mesmo sistema do eu.

$\mathrm{O}$ infinito não aparece como objeto de tematização ou de satisfação das necessidades. Ele revela-se como Rosto, possuindo uma significação ética. "No rosto, no outro brilha de alguma forma a presença enigmática do infinito." $27 \mathrm{Na}$ presença do rosto abre-se uma dimensão do infinito, despertando um desejo que, para se tomar ético, deve reconhecer o outro como absolutamente outrem. 0 desejo só se manifesta na relação social. Este é o modo pelo qual acontece a passagem da idéia do infinito, enquanto estrutura formal, para uma relação concreta, sem constituir uma totalidade, entre o Mesmo e o Outro. $\mathrm{O}$ outro, enquanto infinito, é uma alteridade absoluta que se manifesta concretamenţ na relação ética. O fundamento desta relação é o encontro com um Rosto.

25 “[...] l'intencionnalité est-elle le seul mode de la 'donation de sens'? Le sensé est-il toujours corrélatif d'une thématisation et d'une représentation?" (EN 145).

26 " [...] dans la situation décrite par Descartes où le je pense entretient avec l'Infini qu'il ne peut aucunement contenir et dont il est séraré, une relation appelée idée de l' infin'" (TI 40).

27 Cf. PIVATTO, Pergentino. A ética de Lévinas e o sentido do humano. Veritas, Porto Alegre, v. 37, n. 147 , set. 1992 , p. 341. 
A categoria rosto confronta-se com a noção kantiana de Razão Prática. Para Lévinas, a dimensão ética começa a partir da significação do rosto, desmistificando a filosofia do ego cogito e da ipseidade em detrimento de um outro modo de pensar a alteridade, a partir de uma pura exterioridade. Neste contexto, o outro, na relação, não surge como objeto de tematização. Ao contrário, o brilho da exterioridade, da transcendência no rosto do outro, destitui a consciência como fonte de todo o sentido, ou seja, o eu soberano, no seu isolamento exclusivo de cogito e de seu reino unificante e tematizado, é posto em questão. Esta é uma situação na qual a totalidade se quebra e, ao mesmo tempo, é condicionada. Mas, tal condicionamento não contém um sentido transcendental. O infinito é de outra ordem. $\mathrm{O}$ rosto, enquanto fundamento da lei moral, não é o transcendental. Aliás, possui uma significação sem nenhum contexto formal a priori.

A partir do esquema transcendental é impossivel constituir a verdadeira alteridade do outro. Para Lévinaș, a relação entre outrem e eu não desemboca em um número ou em um conceito a priori. Outrem é infinitamente transcendente e estranho. O seu rosto, a sua presença, rompe com o mundo comum a dois e os mantêm totalmente separados. Não há como pensar a relação em termos de reciprocidade mútua, na forma como Kant concebeu na segunda formulação do imperativo categórico. Não há simetria entre o eu e o outrem. Considerar o outro como um alter ego significa aniquilar a alteridade do outro, sua diferença.

A separação não consiste no fato de que cada indivíduo deva ficar encerrado em si mesmo, no seu egoísmo, isolado, ignorando a transcendência do outro. "Ver o rosto é falar do mundo. A transcendência não é uma óptica, mas o primeiro gesto ético." 28 A visão do rosto não é exatamente uma visão, mas audição e palavra. Falar, ao invés de tematizar, consiste em confessar a alteridade do outro, é acolher a sua expressão, a qual interpela de forma imediata. Pensar significa, antes de tudo, escutar. Nesta perspectiva, é preciso converter a inteligibilidade em hospitalidade e serviço. "A razão e o pensamento começam na obediência ao outro. A liberdade é justificada, sustentada e exaltada pelo outro. E, finalmente a vontade, pela qual Lévinas define a interioridade soberana, se torna 'essencialmente' bondade, fazendo recurso do mundo e da obra como acolhimento e oferta." 29 Isto significa orientar a liberdade através de um mandamento que transcende a dimensão estrutural do eu transcendental.

O rosto, ao trazer a primeira significação, no frente-a-frente, fundamenta a linguagem a qual não serve à razão, mas é a própria razão (TI 228). Assim o rosto, enquanto lugar onde se manifesta a significação original, é a razão prática, a qual comanda e ordena o agir moral. Trata-se de uma significação por excelência, a partir da qual se origina o pensamento, a linguagem. Aliás, é um convite à renovação do próprio pensar filosófico como inseparável da atitude ética.

28 “Voir le visage, c'est parler du monde. La transcendance n'est pas une optique, mais le premier geste éthique" (TI 190). 
Lévinas rejeita o idealismo transcendental kantiano. Ao lado de Nietzsche, de Heidegger e da corrente analítica, ele recusa a dimensão transcendental da filosofia, apresentando as suas próprias razões para o movimento contemporâneo de destranscendentalização. Busca uma nova fundamentação para a sua proposta ética, a saber, fora do caráter apriorístico, racional e autônomo. Lévinas recusa todo e qualquer tipo de discurso idealista que tem a preocupação de construir uma conceituação lógica e coerente e que, no final, acaba por falta de interlocutores. "Ao fundar o discurso como ética, um discurso que não começa pelo verbo nem pela racionalidade, Lévinas não nega a racionalidade do discurso. 0 que pretende é dar um sentido diferente ao racional; o rosto, sendo a primeira significação, é o próprio surgir do racional." 30 No seu entender, de nada serve distinguir formalmente vontade e entendimento, vontade e razão, quarido se decide, desde logo, só considerar como boa a vontade a que adere às idéias claras ou que só se decide por respeito do universal. Contra a identificação da vontade e da razão, que a última intenção do idealismo visa, opõe-se toda a experiência patética da humanidade (TI 239), a saber, a falsa justificação das normas morais, sem nenhum compromisso ético com a alteridade.

A substituição da consciência moral autônoma pelà relação frente-a-frente em que a lei moral vem de fora, modifica a noção de racionalidade. A racionalidade não é mais cálculo, nem um universo controlado por regras e procedimentos. Sem uma estrutura apriorística, ela é a experiência do novo que se realiza no encontro com o outro. Enquanto Kant prioriza a autonomia do eu, Lévinas contrapõe-se invertendo o processo através da heteronomia, em que o outro tem a primazia sobre o eu.

A pergunta que se coloca é esta: como tomar consciência da Lei Moral - "tu não matarás" - que está expressa no rosto do outro? Dito de outro modo, como deverá ser a estrutura da subjetividade para ser capaz de escutar a voz, sem que se pronunciem palavras, de um dizer original? Parece que aqui está o ponto nodal da filosofia de Lévinas. Isto porque para ele a lei moral, o mandamento, que se apresenta na relação frente-a-frente com o outro, é uma ordem que o eu encontra em sua própria resposta. O dizer que vem ao eu é a sua própria palavia ( $\mathrm{AE} 227$ ). Do rosto do outro vem um excesso de significação, no qual se significa o infinito. No entanto, o infinito como tal não aparece àquele que é o seu testemunha, ordena sem contudo se expor; ou seja, fala pela boca de quem recebe o mandamento. "A exterioridade do infinito faz-se de algum modo interioridade na sinceridade do testemunho." 31 O infinito se glorifica no dizer do eu. O mandamento ressoa na boca de quem obedece, revelando-se antes de qualquer, aparecer, não como uma maravilha psicológica, mas como uma modalidade. O mandamento não se anuncia sem o sujeito. Lévinas reconhece que há no ser humano um tendência para o transcendente, para o além do seu pólo. Para explicitar esta inclinação para 0 metafísico ele usa o conceito de desejo. $O$ desejo é a condição de possibilidade da metafísica, mas sem qualquer conotação transcendental.

30 Cf. Nunes, E. P. Lopes, op. cit., p. 63.

31 "L'extériorité de l'Infini se fait, en quelque façon, intériorité dans la sincérité du témoignage" (AE 187). 
O desejo não surge como uma conseqüência de uma iniciativa de um sujeito. Ele vem do outro enquanto estrangeiro. Como se percebe mais uma vez, esta noção defronta-se com a filosofia transcendental kantiana. O problema da alteridade não se resolve a partir da identidade do sujeito racional. O outro não é mais identificado com relação ao eu. Ele procede de um lugar desconhecido. No desejo, o eu põe-se em movimento para o Outro, comprometendo a soberania do eu. Esse movimento para o outro, ao invés de completar ou satisfazer, implica o eu numa conjuntura que precede o racional. A relação com o outro questiona o eu, esvazia o eu de si, abrindo sempre novas possibilidades de interlocução. Desta forma, o eu autônomo, capaz de determinar o sentido da realidade, é destituído do seu poder. Se o eu fosse primordialmente ego cogito, não seria possivel estabelecer uma relação de alteridade. "A transcendência é ética e a subjetividade, que não é no fim de contas o 'eu penso', (como pode parecer à primeira vista), que não é a unidade de apercepçã̉o transcendental - é, à maneira de responsabilidade por Outrem, sujeição à outrem."32 Desse modo, Lévinas supera a concepção kantiana de alteridade. O outro também não é simplesmente um fim em si mesmo assim como o eu - idéia de reciprocidade -, mas absolutamente outro. Desejar é, sobretudo, sair de si para além do horizonte de compreensão do eu. É busca sem retorno, sem correlação. Esse itinerário estabelece uma relação não 'alérgica' com a alteridade.

O desejo, enquanto sentimento primordial, é o início da transformação de um ente em bondade. Bondade que se traduz em resposta e responsabilidade enquanto estrutura fundamental da subjetividade. Lévinas, ao descrever a estrutura ética da subjetividade, coloca como fundamento primeiro e essencial a responsabilidade. A ética não aparece como suplemento de uma base existencial prévia, mas como responsabilidade que brota da subjetividade, para além e anterior à condição ontológica e à consciência transcendental. Aquém do ser se encontra uma subjetividade capaz de escutar a voz sem palavras de um dizer original e que aponta para uma outra dimensão do eu. Prévio ao ato de consciência, anterior ao ser sujeito intencional, o eu já responde a um chamado. A responsabilidade pelo outro ser prescinde da representação conceitual ou da mediação de um imperativo categórico no sentido kantiano do termo.

Veja-se que a filosofia de Lévinas, neste aspecto, encontra-se nas antípodas da filosofia kantiana. Perante a alteridade, o eu transcendental perde suá soberania e deixa de ser o pólo centralizador que determina as regras do conhecimento e da ação moral. Isso no entanto não significa que Lévinas nega a identidade do eu. Ao contrário, procura afirmar a individualidade do sujeito a partir da responsabilidade por outrem. $\mathrm{O}$ eu é incumbido da responsabilidade, com exclusividade, e à qual não pode humanamente recusar. Este encargo é uma suprema dignidade do único. "Unicidade significa aqui impossibilidade de se furtar e de se fazer substituir, na qual se enlaça a própria recorrência do eu."33 $\mathrm{O}$ eu é na medida em que é res-

32 "La transcendance est éthique et la subjectivité que n'est pas en fin de compte le 'je pense' (qu'elle est de prime abord), qui n'est pas l'unité de 'l'aperception transcendentale' - est, en guise de responsabilité pour Autrui, sujétion à autrui" (DVI 113).

33 "Unicité signifie íci impossibilité de se dérober et de se faire remplacer, dans laquelle se noue la recurrence même de je" (AE 73). 
ponsável por outrem. Ele pode substituir a todos, mas ninguém pode substituí-lo. Essa é a sua identidade inalienável de sujeito (EI 108). "O que faz com que a subjetividade seja subjetividade é a responsabilidade que ela tem pelo outro." 34 Desse modo, pode afirmar-se que a responsabilidade individua o eu, pois ninguém pode assumir no seu lugar essa condição.

Para Lévinas, "a subjetividade, ao constituir-se no próprio movimento em que lhe incumbe ser responsável pelo outro, vai até à substituição por outrem. Assume a condição - ou a incondição - de refém. A subjetividade como tal é inicialmente refém; responde até expiar pelos outros." ${ }^{35}$ Nesse sentido, opera uma nova "revolução copernicana" na história da filosofia. Enquanto Kant identifica a transcendência do ser metafísico na imanência do sujeito em ação, cujo caráter ético significa um apelo à autonomia da pessoa, Lévinas procura demonstrar que a verdadeira transcendência imanente acontece não mais a partir da estrutura apriorística da subjetividade monológica. A presença da alteridade provoca uma fissura no eu solipsista, possibilitando uma real transcendência que não significa mais um retorno a si mesmo, mas uma responsabilidade infinita pelo outro. "A é algo que não retorna a $\mathrm{A}$, como na identidade, mas retrocede aquém do seu ponto de partida." 36 É nessa responsabilidade infinita que o eu encontra a sua unicidade, a saber, no transcender para o absolutamente outro, sem qualquer preocupação com a reciprocidade. Este movimento, em direção ao outro, "é o próprio acontecimento da transcendência como vida". 37 Transcendência que se substitui ao outro, para além dos processos de identificação de si.

É assim que a unicidade do eu adquire sentido. O sentido que inspira a ação humana não se encontra no ser, mas no movimento do eu que vai em direção ao outro para instaurar a justiça e a paz, sem retornar a si. A ética não é um sistema filosófico, o ponto de chegada, mas o ponto de partida. Lévinas não acredita que alguém possa recusar tais ideais, mesmo que se sejam declarados como ideais de santidade.

34 BRITO, J. H. Introdução à fundamentação da Metafisica dos costumes, de Immanuel Kant p. 137.

35 "La subjectivité, se constituant dans le mouvement même où à elle incombe d'être responsable pour l'autre, va jusqu'à la substitution pour autrui. Elle assume la condition - ou l'incondition d'otage. La subjectivité comme telle est initialement otage; elle répond jusqu'à expier pour les autres" (EI 106-107).

36 "A ne revient pas, comme dans l'identité, à $\mathrm{A}$, mais recule en deçà de son point de départ" (AE 145).

37 "Ce n'est pas une expérience de l'inégalite posée dans le thème d'une connaissance, c'est l'événement même de la transcendance comme vie" (EN 104). Lopes ao se pronunciar sobre esta questão afirma que a transcendência "no consiste sólo en salir de sí mismo mediante el conocimiento, ni siquiera mediante la moral, una especie de triunfo del altruismo sobre el egoísmo. La trascendencia es, ante todo, trascendencia del ser; no merece tal nombre ninguma acción o pasión referida a un sujeto ya constituido. La trascendencia está antes, o detrás, no como algo que deba buscarse mediante la reminiscencia o el develamiento: ésta seria la obra del ser" (Lopes, op. cit., p. 216). 


\section{Referências bibliográficas}

ARENDT, Hannah. Lições sobre a filosofia política de Kant. Rio de Janeiro: Relume-Dumará, 1993.

BAKIRDJIAN, S. S. Kant y Lévinas: la imposibilidad teorica de la metafisica. In: Stromata, San Miguel, año 37, n. 3-4, jul.-dic., 1981.

BRITO, J. H. Silveira de. Introdução à Fundamentação da Metafisica dos costumes, de I. Kant. Porto: Ediçōes Contraponto, 1994.

_ـ Lévinas, Husserl e a consciência activa. Revista Portuguesa de Filosofia, Lisboa, 1991, p. 87 95.

FABRI, Marcelo. Desencantando a ontologia: subjetividade e sentido ético em Lévinas. Porto Alegre: EDIPUCRS, 1997.

KANT, Immanuel. Crítica da razão pura. Trad. Valério Rohden e Udo Moosburguer. São Paulo: Abril Cultural, $1980.2 \mathrm{v}$.

—_ Fundamentação da Metafísica do Costumes. Trad. Paulo Quintina. Lisboa: Ediçōes 70, 1991.

. Crítica da razão prática. Trad. Artur Morão. Lisboa: Edições 70, 1989.

. Prolegômenos a toda a metafisica futura. Lisboa: Edições 70, 1988.

- Crítica da faculdade do juízo. Rio de Janeiro: Forense Universitária, 1993.

LEBRUN Gérard. Uma escatologia para a moral. In: KANT, Immanuel. Idéia de uma história universal de um ponto de vista cosmopolita. São Paulo: Brasiliense, 1986. p.75-101.

LÉVINAS, Emmanuel. Théorie de l' intuition dans la phénoménologie de Husserl. Paris: J. Vrin, 1930.

. En découvrant P' existence avec Hesserl et Heidegger. Paris: J. Vrin, 1967.

Totalité et infini. Paris: Martinus Nijhoff (Série Biblio-essais), 1971; Totalidade e infinito. Trad.

José P. Ribeiro. Lisboa: Edições 70, 1988.

- Humanisme de I' autre homme. Paris: Fata Morgana (Série Biblio-essais), 1972; Humanismo do outro homem. Trad. Pergentino S. Pivatto (coord.). Petrópolis: Vozes, 1993.

- Autrement qu'être ou au-delà de Pessence. Netherlands: Martinus Nijhoff/La Haye, 1974; De otro modo que ser, o más allá de la esencia. Trad. Antônio Pintor-Ramos. Salamanca: Síguime, 1987.

. Difficile liberté. Paris: Albin Michel (Série Biblio-essais), 1976.

Noms propres. Paris: Fata Morgana (Série Biblio-essais), 1976.

Éthique et infini. Dialogues avec Philippe Nemo. Paris: Fayard, 1982; Ética e infinito. Trad.

Fhilippe Nemo. Lisboa: Edições 70, 1988.

- Le temps et Pautre. Montpellier: Fata Morgana, 1979; El tiempo y el otro. Trad. José, L.

Pardo Torío. Barcelona: Paidós, 1993.

— Dios, la muerte y el tiempo. Trad. Maria L. R. Tapia. Madrid: Cátedra, 1994.

1994.

L'intrigue de l'infini. Textes réunis et présentés par Marie-Anne Lescourret. Flammarion,

— . De Dieu qui vient a I'idée. Paris: J. Vrin, 1982.

. Transcendência e Inteligibilidade. Trad. José F. Colaço. Lisboa: Edições 70, 1991.

Entre nous. Essais sur le Penser-à-l' autre. Paris: Bemard Grasset, 1991.

. Entre nós. Ensaios sobre a alteridade. Trad. Pergentino S. Pivatto (coord.). Petrópolis: Vozes,

1997.

- Transcendance et hauteur. Bulletin de la Société Française de Philosophie, n. 56, p. 89-101, 1962. Discussōes: 101-111.

- Infini. In: Encyclopédie universelle. Paris, 1970. v. 8, p. 991-994.

LOPEZ, J. M. Aguilar. Trascendencia y Alteridad. Estudio sobre E. Lévinas. Pamplona: Ediciones Universidad de Navarra. 1992.

MECA, Diego Sánchez. Martin Buber. Fundamento existencial de la intercomunication. Barcelona: Editorial Herder, 1984.

NUNES, Etelvina. $O$ outro e o rosto. Problemas da alteridade em Emmanuel Lévinas. Braga: Publicaçöes da Faculdade de Filosofia da UCP, 1993.

PELIZZOLI, Marcelo Luiz. A relação ao outro em Husserl e Lévinas. Porto Alegre: EDIPUCRS, 1994.

13, 1995, p. 21-34. 
PIVATTO, Pergentino, S. La relation a la transcendance dans P'oeuvre d'Emmanuel Lévinas. Paris (tese de doutorado), 1980.

A ética de Lévinas e o sentido do humano - crítica à ética ocidental e seus pressupostos. Veritas, Porto Alegre, v. 37, n. 147, set. 1992, p. 325-363.

A nova proposta ética de Emmanuel Lévinas. In: Cademos da FAFIMC. Viamão. V. Especial, n. 13, 1995, p. 47-62.

REGUERA, G. Bello. La ética de la alteridad en la escena contemporánea. Anales de la Cátedra F. Suárez, n. 28, 1988.

- La construccion de la alteridad en Kant y Lévinas. In: MUGUERZA, Javier, ARAMAYO, R. Rodriguez. Kant después de Kant. Madrid: Tecnos, 1989. p. 576-604.

SCRUTON, Roger. Kant. Trad. Maria Margarida Carrinho. Lisboa: Publicações Dom Quixote,1983.

SOUZA, Ricardo Timm. Totalidade e desagregação. Sobre as fronteiras do pensamento e suas alternativas. Porto Alegre: EDIPUCRS, 1996.

SUSIN, Luiz Carlos. O homem messiânicơ. uma introdução ao pensamento de Emmanuel Lévinas. Porto Alegre/Petrópolis: EST/Vozes, 1984. 365-377. 